\title{
Near-seafloor magnetic mapping of off-axis lava flows near the Kairei and Yokoniwa hydrothermal vent fields in the Central Indian Ridge
}

\author{
Masakazu Fujii ${ }^{1,2^{*}}$ (I) and Kyoko Okino ${ }^{3}$
}

\begin{abstract}
The Kairei (KHF) and Yokoniwa hydrothermal fields (YHF) are hosted in mafic as well as ultramafic rocks distributed at an off-axis volcanic knoll of the Central Indian Ridge. Despite intensive investigations, their geological and geophysical background is still debated. Here, we show the results of near-seafloor magnetic anomaly surveys conducted using a submersible. We investigated the bulk magnetization of the hydrothermally altered zone and the surrounding lava flows and evaluated their intensities compared with previously reported values at axial areas of seafloor spreading environments. The KHF is characterized by low coherence between observed and modeled anomalies and low values of magnetization. This result suggests that magnetic minerals within basaltic lava flows were likely altered by hydrothermal fluid circulation. The variation pattern in the observed magnetic anomalies above the lava flows is in phase with that of the modeled magnetic anomalies for the simple assumption that the magnetization direction is parallel to the geomagnetic field. This result suggests that these lava flows preserve normal magnetic polarity corresponding to the Brunhes Chron. The estimated magnetic-anomaly-derived absolute magnetizations show a reasonable correlation with the natural remanent magnetizations of rock samples collected from the seafloor of the same region; their relationship is consistent with previously reported datasets from the Mariana Trough and Mid-Atlantic Ridge. The estimated magnetization intensity reaches $20 \mathrm{~A} / \mathrm{m}$ in the study area, which is clearly greater than those of previously reported off-axis areas, suggesting that recent volcanic eruption may have occurred in these off-axis areas. The high magnetization distributions are commonly observed at the bottoms of the western slope from the KHF and YHF. This finding provides new insight into the distribution of highly magnetized lava flows in the off-axis areas and indicates the distribution of recent off-axis volcanic activities, which is potentially linked to the sub-seafloor hydrothermal circulation.
\end{abstract}

Keywords: Seafloor hydrothermal system, Marine magnetic anomaly, Off-axis lava flow, Central Indian Ridge, Kairei site, Yokoniwa site

\section{Introduction}

Hydrothermal circulation within the oceanic lithosphere is a fundamental process in submarine volcanic systems such as mid-ocean ridges and essentially affects the solidEarth cooling, ocean temperature, and material cycles

\footnotetext{
*Correspondence: fujii.masakazu@nipr.ac.jp

${ }^{1}$ National Institute of Polar Research, 10-3 Midoricho, Tachikawa, Tokyo 190-8518, Japan

Full list of author information is available at the end of the article
}

(e.g., Elderfield and Schultz 1996). The Kairei hydrothermal field (KHF), known as the first confirmed active seafloor hydrothermal system of the Central Indian Ridge (CIR) since its discovery in 2000 (Gamo et al. 2001), is situated in the southernmost segment of the CIR, namely CIR-S1, near the Rodrigues ridge-ridge-ridge triple junction (Fig. 1). This hydrothermal system is likely related to water-rock reactions of mafic as well as ultramafic host rocks because high $\mathrm{H}_{2}$ and $\mathrm{CH}_{4}$ gas content of 
vent fluids was observed, and the presence of ultramafic rocks was confirmed $10-20 \mathrm{~km}$ from the vent field (Gallant and Von Damm 2006; Kumagai et al. 2008; Nakamura et al. 2009; Okino et al. 2015). The Yokoniwa hydrothermal field (YHF) was identified in 2009 in the same segment of the CIR-S1 (Fujii et al. 2016a; Fig. 1). This field is located on top of a shallow dome-like massif developed between two nodal basins at the northern end of CIR$\mathrm{S} 1$ and the southern end of CIR-S2, which is recognized as a non-transform offset massif known as Yokoniwa Rise (Okino et al. 2015). Previous sea-surface magnetic anomaly studies have identified the Brunhes/Matuyama boundary along the eastern off-axis areas of CIR-S1 and S2 (Honsho et al. 1996; Sato et al. 2009; Okino et al. 2015; Fig. 2b, c), suggesting that the Yokoniwa Rise formed in the Brunhes normal chron ( 0.78 Ma). The YHF has been suggested to be an inactive mature hydrothermal system hosted by highly serpentinized ultramafic rocks based on near-seafloor magnetic anomalies and rock magnetic studies as well as visual observation of diminishing low-temperature venting and small dead chimneys (Fujii et al. 2016a, b).
CIR-S1, where the KHF and YHF occur in an off-axis area, is a $20-\mathrm{km}$ long segment with a deep axial valley. Undeformed volcanic cone structures and volcanic knolls are distributed within a neo-volcanic zone (Fig. 2a). The segment shortens with seafloor age in the off-axis area, which implies that CIR-S1 was newly created during the evolution of the triple junction (Honsho et al. 1996; Mendel et al. 2000). The off-axis knoll with the KHF, known as the Hakuho knoll, is composed entirely of pillow and sheet lavas (Fig. 1). Magnetization distribution deduced from sea-surface magnetic anomalies shows a relatively low value at the Hakuho knoll owing likely to a thin extrusive overlying layer or a hydrothermally altered extrusive layer. The YHF is located on the side of a more magnetized region aligned parallel to the adjacent nontransform offset and may have originated from enhanced magnetization as a result of serpentinization of the ultramafic body (Fujii et al. 2016a, b). Submersible and dredge surveys showed that gabbro and serpentinized peridotite are extensively exposed in a further off-axis area (eastern side) from the Hakuho knoll (Nakamura et al. 2009; Okino et al. 2015; Sato et al. 2015; Fig. 1). Nakamura et al.

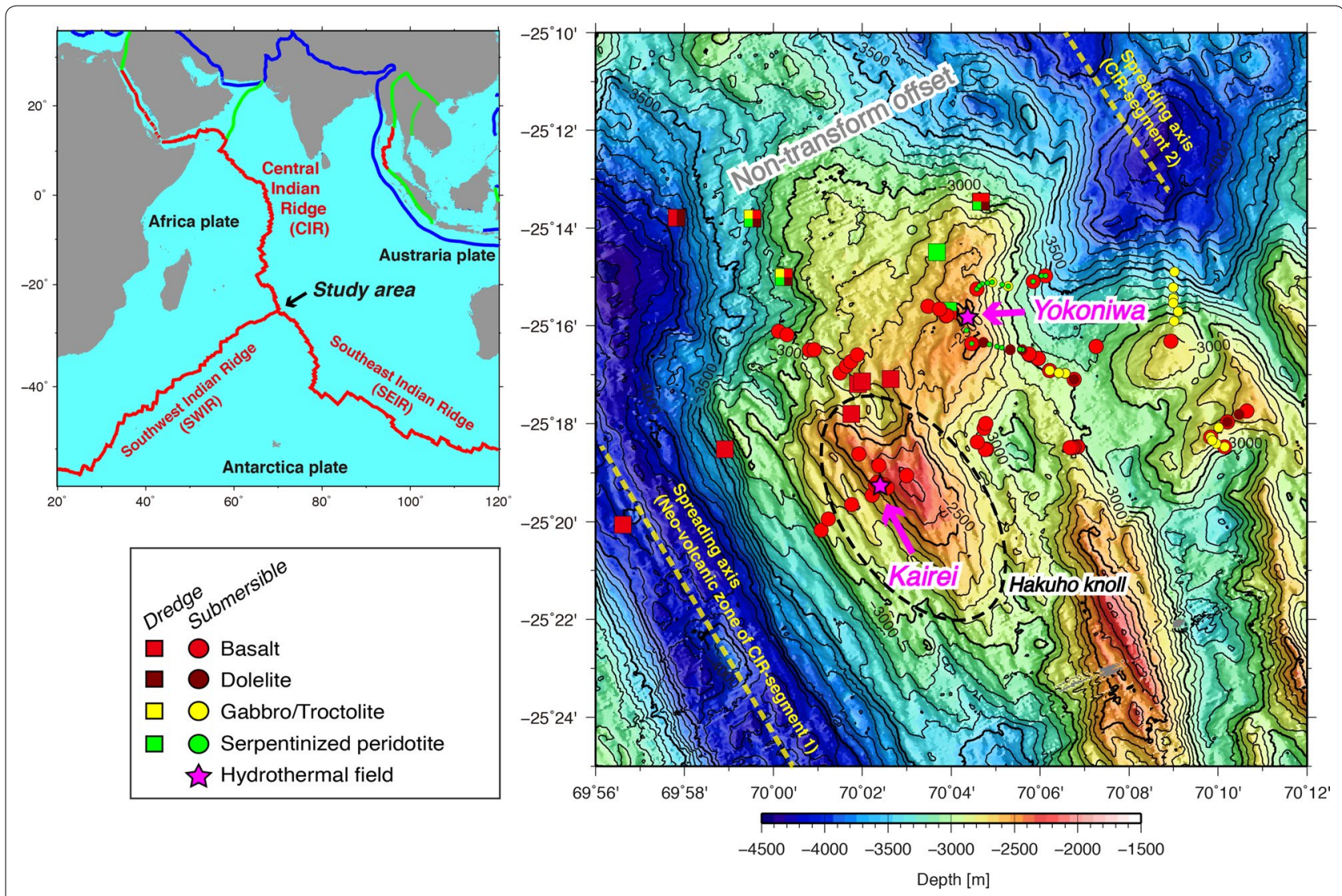

Fig. 1 Geological background and seafloor bathymetry of the study area. Rock samples collected by dredge (squares) and submersible (circles) are shown as basalt (red), dolerite (brown), gabbro (yellow), and serpentinized peridotite (green). Locations of the Kairei and Yokoniwa hydrothermal fields are shown as purple stars 

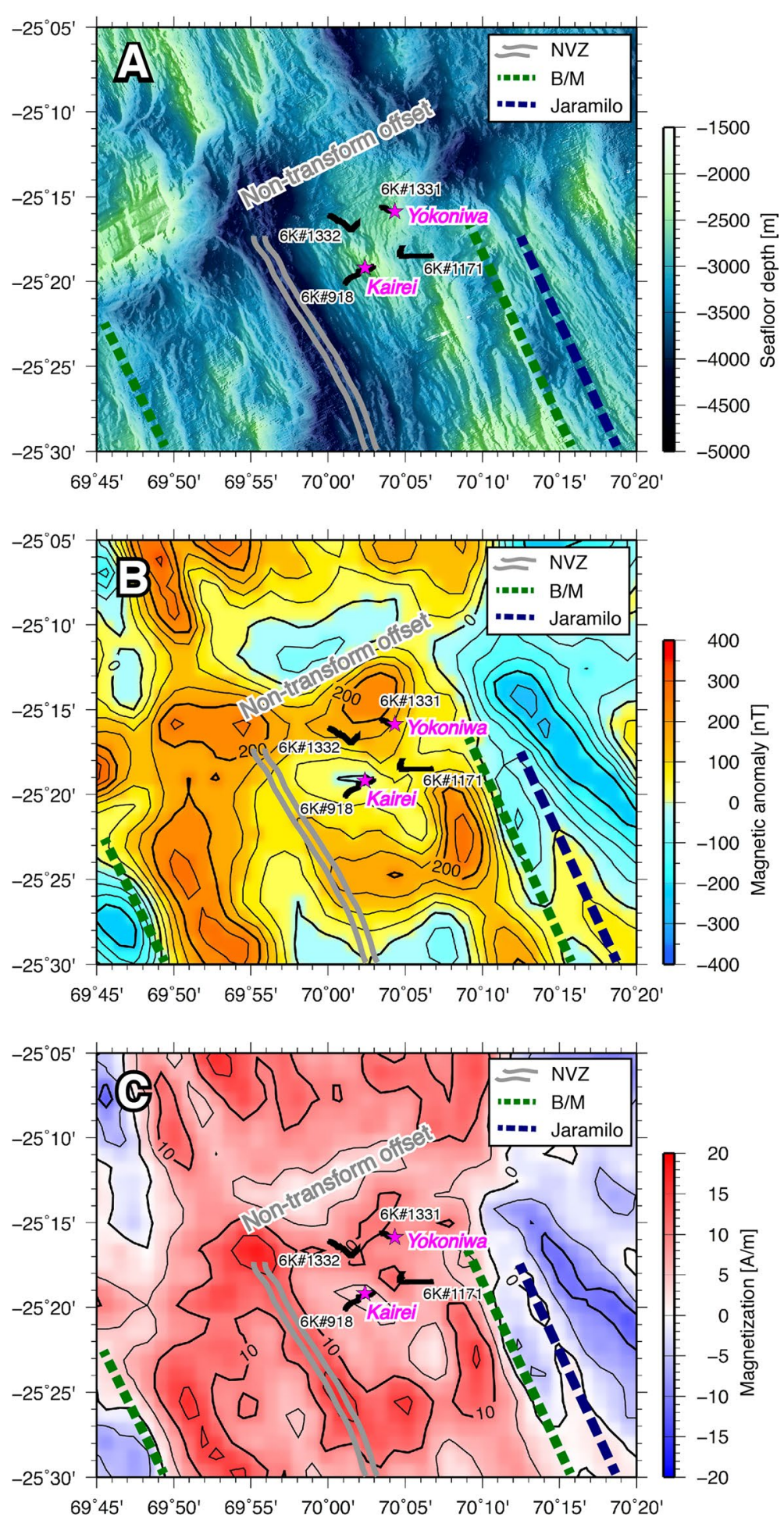

Fig. 2 Survey tracks to obtain studied near-seafloor magnetic anomalies near the Kairei and Yokoniwa hydrothermal fields of the Central Indian Ridge overlaying a bathymetry, b magnetic anomaly, and c magnetization distribution maps (modified from Okino et al. 2015). Dives 6K\#918, 6K1171, and 6K\#1332 were conducted in an off-axis area of segment-1 of the Central Indian Ridge. NVZ neo-volcanic zone, B/M: Brunhes-Matuyama boundary $(0.78 \mathrm{Ma})$; Jaramilo: magnetic isochron of Jaramilo chron 1 r.1 (0.99-1.07 Ma) 
(2009) proposed a theoretical model of KHF genesis suggesting that both troctolite-seawater and basalt-seawater interactions can be sources of $\mathrm{H}_{2}$-rich fluids. Whether troctolites $15 \mathrm{~km}$ from the KHF can react is still debated. Fujii et al. (2016a) proposed a three-stage formation model of ultramafic-hosted hydrothermal systems and speculated that magmatic intrusion at depth could be a driving force for hydrothermal circulation; however, shallow basaltic volcanism near the YHF has also been reported and could be an alternative driving force (Fig. 1). The geological and geophysical background factors of the hydrothermal system such as circulation style, driving force, and fluid pathway remain to be confirmed in this segment.

In this study, we explored off-axis lava flows near the KHF and YHF in CIR-S1. Near-seafloor magnetic anomaly data were obtained by using a submersible. To determine the lava freshness, we investigated the bulk magnetization of the lava flows and evaluated their intensities compared with previously reported values at an axial area of a spreading environment. This study provides insight into the distribution of highly magnetized lava flows, which indicate the distribution of recent extrusions and are potentially linked to sub-seafloor hydrothermal circulation as a heat source.

\section{Method}

We performed near-seafloor magnetic surveys surrounding the KHF and YHF using the submersible SHINKAI 6500 (6K) during three scientific cruises of the R/V Yokosuka; YK05-16, YK09-13, and YK13-03 (Fig. 2). Dive $6 K \# 918$, during YK05-16, covered the eastern slope of the axial valley and the off-axis knoll at 2200-3000 m depth, where the KHF is located. Dive 6K\#1171, during YK0913, covered the eastern side of the KHF at the foot of the eastern slope at 2900-3200 m depth. Dive 6K\#1331, during YK13-03, covered only the western side of the YHF at 2400-2700 m depth. Dive 6K\#1332, also during YK1303, covered the northern side of the KHF and the western side of the YHF at 2700-3200 m depth.

Three components of the magnetic field were successfully measured by using a three-axis fluxgate-type magnetometer that was rigidly fixed to the front side of the submersible. Attitude data of heading, pitch, and roll were obtained by using a gyrocompass and a motion sensor (Octans, iXblue Inc., USA). The observed data were first corrected for the effects of induced and permanent magnetizations of the submersible to obtain regional magnetic anomalies after subtraction of the International Geomagnetic Reference Field (IGRF; Isezaki 1986). The data for calibration were obtained during the helical loops performed spontaneously at mid-depth above the seafloor. All dive surveys were navigated by acoustic ranging operated in the sea-surface vessel by using a super-short baseline positioning system. The magnetic data were collected at an altitude of a few to several tens of meters. To conduct the following two-dimensional analyses, the data along the dive tracks were projected onto a straight line. The directions of the $x, y$, and $z$ components were defined as being parallel to, perpendicular to, and downward of the projection line, respectively. The $y$ component actually had some variation, implying that the structure is not exactly two-dimensional. These anomalies were produced mainly by local topography and the vertical motion of the submersible.

The two-dimensional forward method combined with frequency analysis was applied to estimate the absolute magnetization under consideration of topography and altitude variation (Fujii et al. 2015; 2016a; Honsho et al. 2009). Absolute magnetization intensity was estimated from the ratio of the observed magnetic anomaly to the synthetic anomaly computed for a $1-\mathrm{A} / \mathrm{m}$ magnetization intensity representing the unit magnetization intensity of the seafloor. The synthetic anomaly was calculated by using a two-dimensional forward calculation based on a polygonal body (Talwani and Heirtzler 1964). The upper boundary of the magnetized layer was constrained by the topographic surface, which was defined by the depth and altitude of the vehicle. The magnetized layer was assumed to be uniformly magnetized with infinite half-space and a magnetization direction parallel to the geocentric axialdipole field, showing an inclination of $-43^{\circ}$ and a declination of $0^{\circ}$. Absolute magnetization was estimated at 16-m intervals along the track using a 256-m-wide sliding window. Spectra were then averaged over wavelengths between 43 and $256 \mathrm{~m}$ to obtain a ratio of observed to synthetic anomalies, together with error, coherency, and phase. These calculations were applied to all sets of the segments for the $x$ and $z$ components. The averaged values between the $x$ and $z$ ratio of observed to synthetic anomalies were adopted as our best estimate of absolute magnetization intensity. Estimations with a coherency greater than 0.5 in both components were retained for further interpretation. The magnetization polarity was regarded as normal polarity for the phases between $-30^{\circ}$ and $30^{\circ}$.

Previously reported magnetic data along 6K\#1331 from Fujii et al. (2016a) was reanalyzed by using the same analytical condition and assumption mentioned above in order to discuss the magnetization intensity and distribution in comparison with the KHF.

The geological feature of seafloor surface along the dive tracks was constrained by examining video and still camera records for each dive. In some limited areas, no visual observation of the surface geology was obtained because of the higher altitude of the vehicle. Route maps of dive 
$6 \mathrm{~K} \# 918$ have been previously reported by Kumagai et al. (2008).

\section{Results}

Three components of the magnetic field were successfully measured near the KHF and YHF. The maximum amplitude of observed magnetic anomalies along the $6 \mathrm{~K} \# 1171$ and $6 \mathrm{~K} \# 1332$ dive surveys reached $5000 \mathrm{nT}$. In contrast, that of $6 \mathrm{~K} \# 918$ reached 10,000 nT (Fig. 3). The contribution of magnetic sources shallower than $50 \mathrm{~m}$, particularly those shallower than $10 \mathrm{~m}$, was significant for the observed short-wavelength anomaly variations at an altitude of a few to several tens of meters (Fujii et al. 2016a; Honsho et al. 2009). We tested signal sensitivity for several layer thicknesses based on forward modeling. Therefore, variation in the observed magnetic anomalies reflects mainly the magnetization distribution of the uppermost crust, which geologically is the accumulation of lava flows and massive lavas covered by thin sediment (Fujii et al. 2016a; Honsho et al. 2009).

The results of the magnetization solution estimated from the observed anomalies along 6K\#918 were compared with bathymetric signatures, sampled rock, and hydrothermal fields, as shown in Fig. 3. The estimated magnetization intensity with high coherency $(>0.5)$ was 4-28 A/m (Fig. 3). Nearly all showed a phase of normal polarity at $-30^{\circ}$ to $30^{\circ}$ in both the $x$ and $z$ components, representing the acquisition of basement remanence during the normal geomagnetic polarity period. Strong estimated magnetization higher than $10 \mathrm{~A} / \mathrm{m}$ along $6 \mathrm{~K} \# 918$ was observed only on the western part of the KHF (0.3$2.0 \mathrm{~km}$ area in Fig. 3), where basaltic rock samples were collected (Figs. 1 and 3). Local geological conditions in this region show mainly piles of flat or lobate sheet flows and some sediment-covered lavas (Fig. 4). Seafloor shallower than the KHF showed an estimated magnetization intensity of up to $10 \mathrm{~A} / \mathrm{m}$ (Fig. 3). In contrast to the highly magnetized seafloor, the area of the KHF and its western slope show low coherency and a complicated phase (2.0$3.3 \mathrm{~km}$ area in Fig. 3) owing mainly to low signal-to-noise ratio caused by the weakly magnetized uppermost crust. Such low-coherence estimations can also be caused by changes in basement lithology or magnetization direction owing to block rotation in addition to geometric error caused by sediment burial. Local geological conditions in this region show reddish sediments and hydrothermal signatures such as dead and active chimneys and unique ecosystems (Kumagai et al. 2008; Fig. 4).

The estimated magnetization intensity with high coherency along $6 \mathrm{~K} \# 1331$ was $3-20 \mathrm{~A} / \mathrm{m}$. Higher values of estimated magnetization were locally observed mid-depth of the survey track around the sites where basaltic lava samples 1331R03 and 1331R04 were collected (0.7-1.0 km area in Fig. 5). Nearly all showed a phase of normal polarity in both the $x$ and $z$ components. Local geological conditions in this region show massive lava flows (Fig. 6) generally in the deeper western area, although whitish sediment covering seafloor is partly dominant (Fig. 6). From the bottom to top of the steep slope toward the YHF, the analytical results of the magnetic anomaly generally show low coherency and a complicated phase, and the magnetization values are less than $5 \mathrm{~A} / \mathrm{m}$ even for data with high coherency (Fig. 5). In this slope, brownish sediments with black blocky rocks were observed; these rocks were too weak for the vehicle manipulators to grab. On top of the Yokoniwa Rise, active hydrothermal fluid shimmering with maximum temperature of $4.2{ }^{\circ} \mathrm{C}$ and several dead chimneys were found, as reported in the 6 K\#1176 dive on November 14, 2009, and discussed by Fujii et al. (2016a).

The estimated magnetization intensity with high coherency along $6 \mathrm{~K} \# 1171$ was generally $4-11 \mathrm{~A} / \mathrm{m}$ (Additional file 1: Figure S1). Data with a phase of normal polarity in both the $x$ and $z$ components were observed at only a few places. The collected rock samples along the survey tracks of the $6 \mathrm{~K} \# 1171$ are all basaltic lavas (Fig. 1).

The estimated magnetization intensity with high coherency along 6K\#1332 was 4-15 A/m (Additional file 2: Figure S2). Those with a phase of normal polarity in both the $x$ and $z$ components reached a maximum of $11 \mathrm{~A} / \mathrm{m}$. The collected rock samples along the survey tracks of the 6K\#1332 are all basaltic lavas (Fig. 1).

\section{Discussion}

\section{Magnetic signature of Kairei hydrothermal field}

The KHF is characterized by low coherence between observed and modeled anomalies under a simple assumption of magnetization direction and source geometry in addition to low magnetization intensity deduced from magnetic anomalies (Fig. 3). This result indicates that the KHF magnetization is less than that of the surrounding seafloor. The KHF is likely hosted by basaltic lava. The basaltic lava samples were widely collected around the KHF (Fig. 3). The major element composition of these samples (6K\#918R02, 6K\#918R03, and 6K\#918R10) was analyzed by microprobe analysis of glass chips (Kumagai et al. 2008); the results demonstrated that all lava samples near the KHF are tholeiite with $50.9-51.5 \mathrm{wt} \% \mathrm{SiO}_{2}$, 0.02-0.05 wt $\% \mathrm{~K}_{2} \mathrm{O}, 2.7-3.0 \mathrm{wt} \% \mathrm{Na}_{2} \mathrm{O}, 8.1-8.4 \mathrm{wt} \%$ $\mathrm{FeO}$, and $1.06-1.19 \mathrm{wt} \% \mathrm{TiO}_{2}$ (Additional file 5: Table S1; Additional file 1: Figure S1).

The general correlation between reduced crustal magnetization and hydrothermal activity in basalt-hosted systems has been well documented in the following locations: in mid-ocean ridges (MORs); on the Trans-Atlantic Geotraverse (TAG) site developed along the detachment 


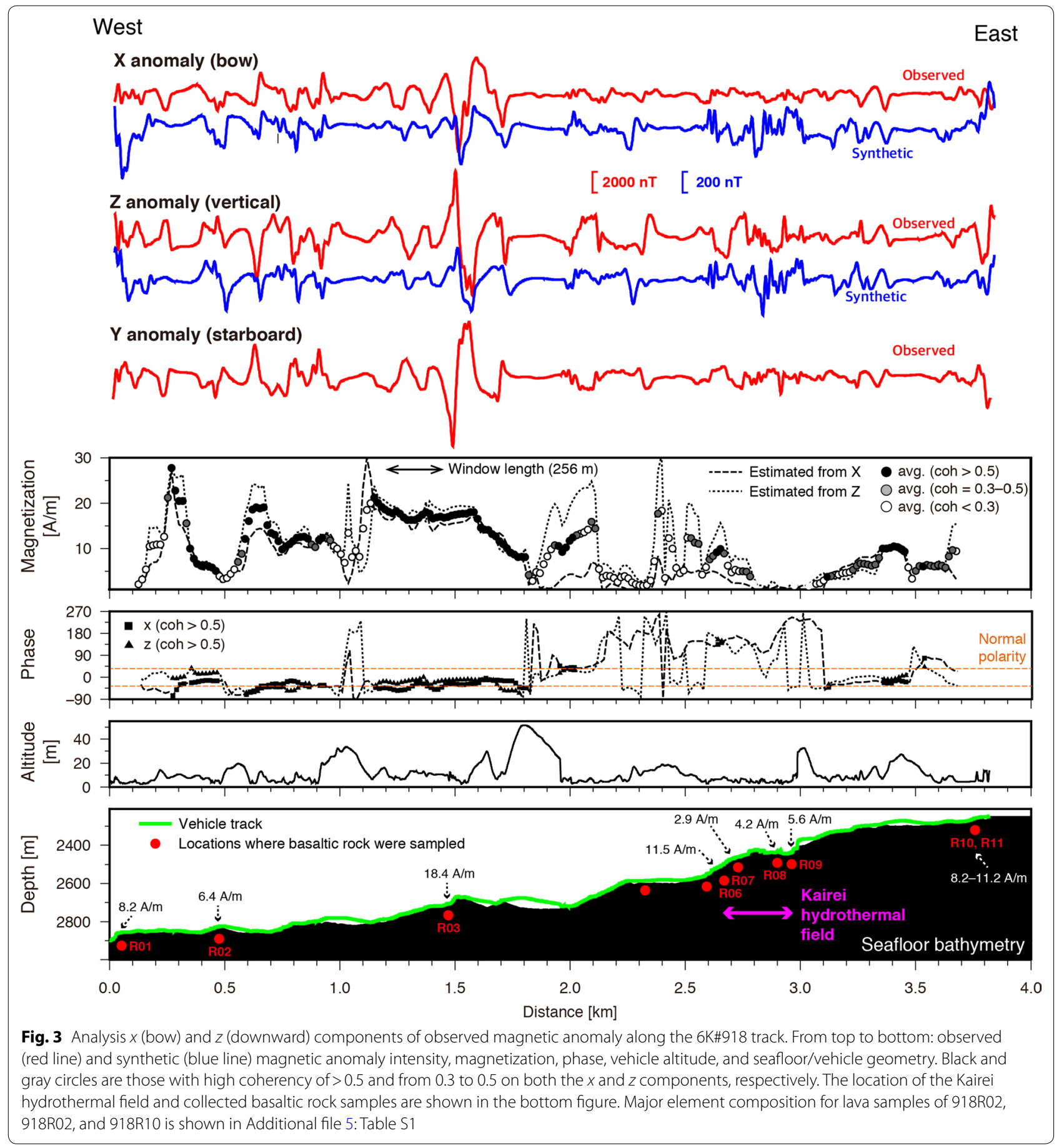

faults of the northern Mid-Atlantic Ridge (MAR; Tivey et al. 1993); the Krasnov site within the axial volcanic ridge near the axial valley wall of the mid-MAR (Szitkar et al. 2014); the $4^{\circ} 48^{\prime} \mathrm{S}$ area within the axial rift on very fresh lavas in the southern MAR including the Comfortless Cove, Turtle Pits, and Red Lion sites (Tivey and Dyment 2010); the Endeavour Field and Raven Field developed within the axial rift valley of the Juan de Fuca Ridge (JFR; Tivey and Johnson 2002; Tivey et al. 2014); and a hydrothermal site on the southwestern Indian Ridge (SWIR; Zhu et al. 2010). Moreover, it was clearly demonstrated that reduced magnetization zones associated with hydrothermal areas are accompanied by basalt to andesite-hosted systems in the following regions: in 


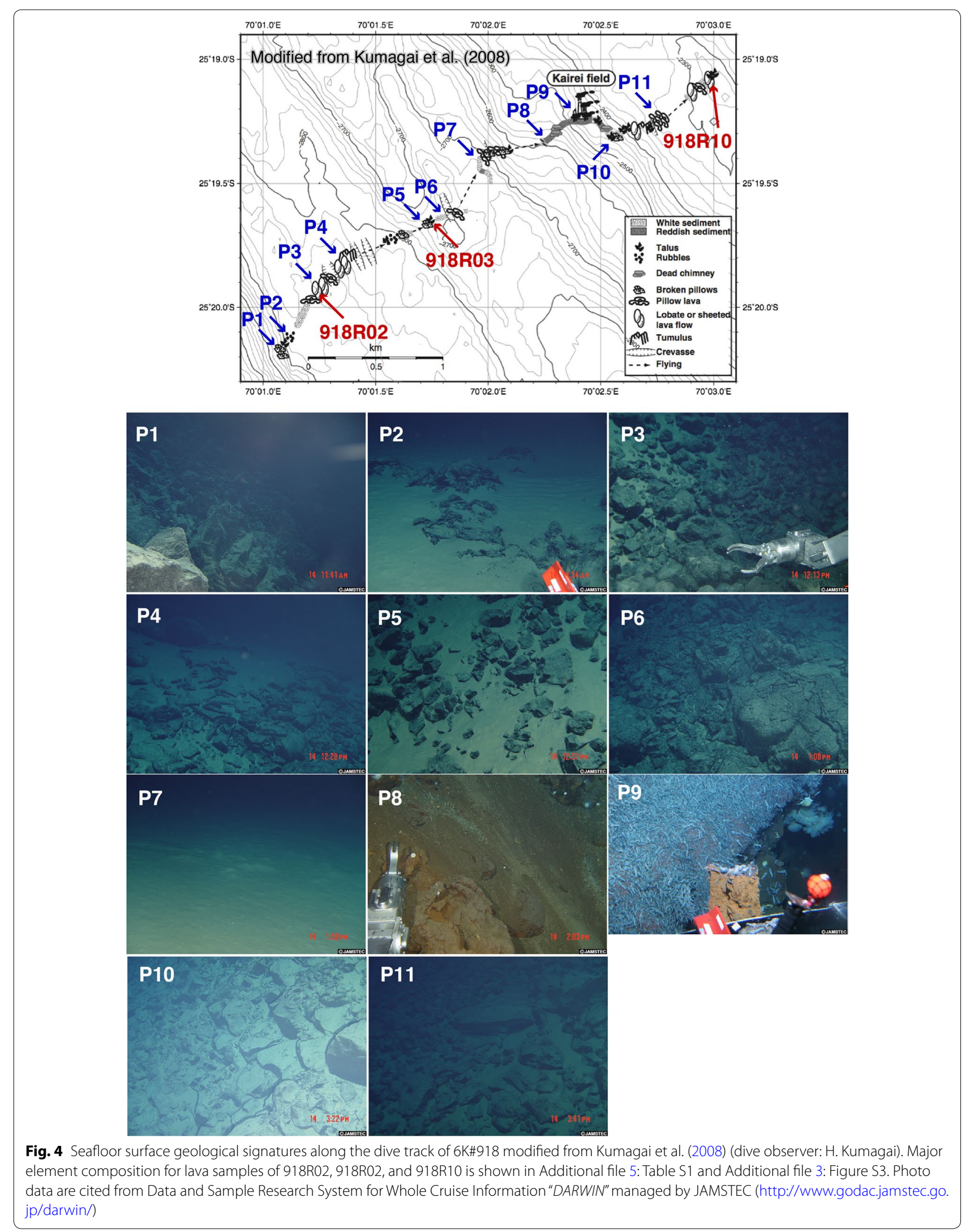




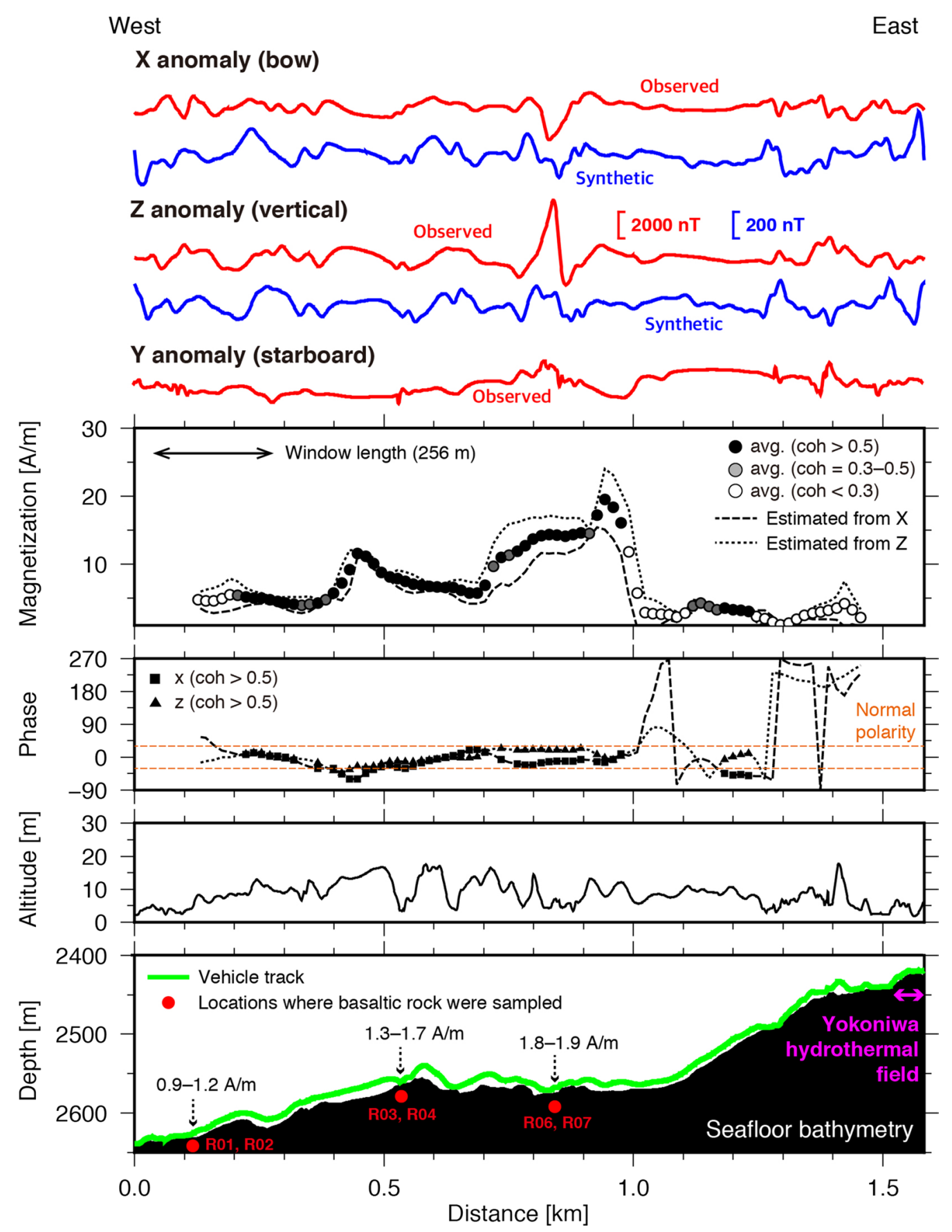

Fig. 5 Analysis $x$ (bow) and $z$ (downward) components of observed magnetic anomaly along the 6K\#1331 track (reanalyzed after Fujii et al. 2016a). From top to bottom: observed (red line) and synthetic (blue line) magnetic anomaly intensity, magnetization, phase, vehicle altitude, and seafloor/ vehicle geometry. Black and gray circles are those with high coherency of $>0.5$ and from 0.3 to 0.5 on both the $x$ and $z$ components, respectively. The locations of the Yokoniwa hydrothermal field and collected basaltic rock samples are shown in the bottom figure. Magnetic and physical properties for lava samples of 1331R01, 1331R02, 1331R03, 1331R04, 1331R06, and 1331R07 are shown in Table 1

back-arc regions; at the Snail and Yamanaka sites along a back-arc spreading center; at the Archean site at the foot of an axial high; and at the Pika and Urashima sites on an off-axis knoll of the Southern Mariana Trough (Fujii et al.
2015) as well as at the Hakurei Field along the caldera wall of the Izu-Ogasawara arc-back-arc (Honsho et al. 2013); at the Brothers Field of the Kermadec intraoceanic arc volcano (Caratori Tontini et al. 2012); and at sites of 

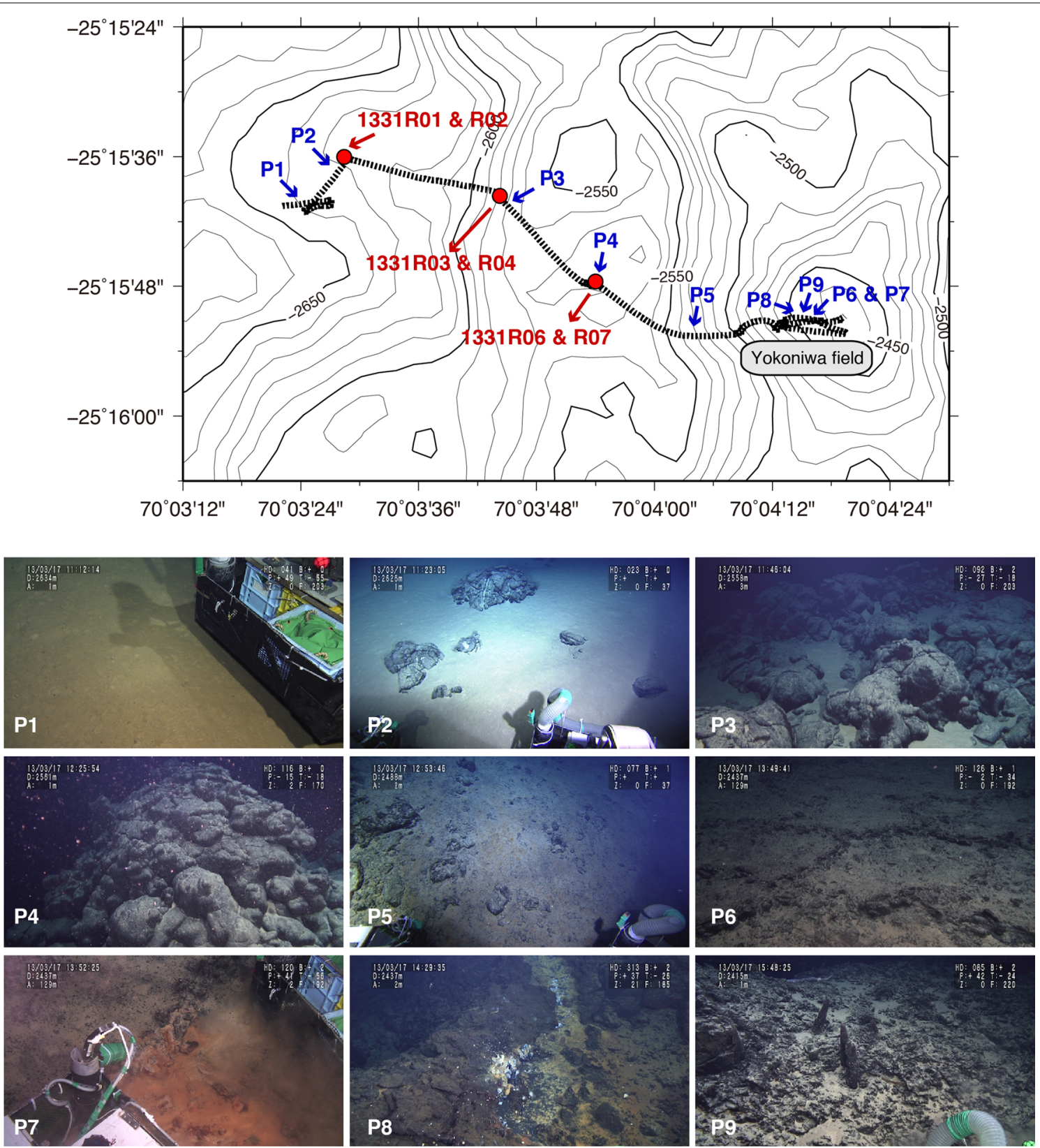

Fig. 6 Seafloor surface geological signatures along the dive track of 6K\#1331 (dive observer:T. Sato). Magnetic and physical properties for lava samples of 1331R01, 1331R02, 1331R03, 1331R04, 1331R06, and 1331R07 are shown in Table 1 and Additional file 4: Figure S4)

the Palinuro volcano on the Aeolian volcanic arc (Caratori Tontini et al. 2014a, b; Szitkar et al. 2015).

Four possible factors are generally considered for producing magnetic lows related to hydrothermal activity: (i) alteration of magnetic minerals (titanomagnetite) within the volcanic basement rock, (ii) accumulation of nonmagnetic hydrothermal deposits, (iii) thermal demagnetization, and (iv) self-reversal. It is considered that the primary process causing weak magnetization is alteration of the host rock with highly corrosive hydrothermal fluid, which altered the magnetic mineral (titanomagnetite) that carries strong natural remanent magnetization (NRM) in volcanic rock to less magnetic or nonmagnetic mineral phases (e.g., Hochstein and Soengkono 1997; Irving 1970; Johnson and Atwater 1977; Hall 1992; Ade-Hall et al. 1971; Watkins and Paster 1971; Fujii et al. 2018). The presence of thick hydrothermal deposits increases the distance between the magnetic field 
measurements and the underlying magnetized basement rocks, resulting in an apparent magnetic low (Szitkar et al. 2014). Thermal demagnetization is also a possible source for reduced magnetization if the subsurface temperature beneath a vent site approaches the Curie temperature of the mineral carrying the magnetic signal, as reported in an early magnetic study of Wooldridge et al. (1992). Reduced magnetization near the Kairei site is widely distributed toward the west even in the area where active hydrothermal venting has not been observed, and therefore, thermal demagnetization is not likely the main cause of magnetization low. Demagnetized zones at both active and inactive vent sites have been also confirmed in the southern Marian Trough (Fujii et al. 2015), the Endeavour Field in the JFR (Tivey and Johnson 2002), and the Krasnov site in the MAR (Szitkar et al. 2015). These results suggest that hydrothermal alteration rather than elevated temperatures should be the primary mechanism for the reduced crustal demagnetization. Furthermore, Tivey et al. (2014) demonstrated that discrete areas of reduced magnetization of the Endeavour Field in the JFR are associated with active and inactive hydrothermal vent deposits in consideration of high conductive heat flow. Another possibility for the magnetic low over hydrothermal fields is self-reversed chemical remanent magnetization (CRM), which has been discussed for the last 40 years (e.g., Verhoogen 1956; O’Reilly and Banerjee 1966). Self-reversal could be produced during extreme low-temperature oxidation (maghemitization) of titanomagnetite by ionic reordering. A recent study of oxidized basalts recovered at nine drilling sites in the Pacific Ocean indicated that very high oxidation states $(z>0.9)$ and relatively high $\mathrm{Ti}$ contents $(x>0.6)$ are needed to produce natural self-reversed components and that selfreversed magnetization is not a general feature of the magnetization carried by oceanic basalt (Doubrovine and Tarduno 2006).

Our results of these magnetic field surveys and previous studies suggest that the reduced magnetization at the KHF indicates alteration of titanomagnetites within volcanic basement rock and/or accumulation of hydrothermal deposits. The area of the KHF (2.7-3.0 km area in Fig. 3) clearly shows very low, near null magnetization and strong correlation with active vents and hydrothermal ecosystems (Fig. 4). It is noted that the area of very low magnetization extends to the western slope from the KHF (2.0-2.7 km area in Fig. 3). Reddish sediments as well as broken lava flows were observed in this area (Fig. 4), implying that accumulated hydrothermal deposits and/or previous hydrothermal alteration of the crust can play roles in the very weakly magnetized crust. Shallow exposure of an ultramafic body covered by very thin extrusions may exist, although geological observation shows basaltic lavas widely distributed in this field; no ultramafic rocks were collected (Figs. 1 and 4).

\section{Off-axis lava flows near the Kairei and Yokoniwa hydrothermal fields}

The variation pattern in observed magnetic anomalies above the lava flows on the western slope and east side of the KHF is in phase with that of synthetic magnetic anomalies assuming an infinite source layer with magnetization parallel to the geocentric axial-dipole field (Fig. 3). The magnetization estimates in the lava-dominant area at the bottom of the western slope of the YHF also show good coherence between the observed and synthetic magnetic anomalies (Fig. 5). The solutions collected along the dives of the $6 \mathrm{~K} \# 1171$ and $6 \mathrm{~K} \# 1332$ partly show similar signatures. These results suggest that these lava flows, erupted during a recent normal polarity period, preserve normal magnetization at the initial stage of cooling. This result is consistent with previous sea-surface magnetic surveys, which identified the Brunhes/Matuyama boundary along the eastern off-axis areas (Honsho et al. 1996; Okino et al. 2015; Sato et al. 2009; Fig. 2). Therefore, it is considered that these lavas likely erupted during the Brunhes normal epoch and acquired normal polarity thermoremanent magnetization (TRM).

We practically utilized the estimations of magnetization with high coherency $(>0.5)$ and normal polarity $\left(-30^{\circ}\right.$ to $\left.30^{\circ}\right)$ in both the $x$ and $z$ components for the following discussion and regarded them as a reliable estimate for magnetic signatures of the extrusive lavas with normal polarity, based on the study by Honsho et al. (2009) (Fig. 7). The estimated magnetization intensity reached $20 \mathrm{~A} / \mathrm{m}$ at the bottoms of the western slopes of the KHF and YHF (Figs. 3, 5, and 7), which is suggestive of recent volcanic activity compared with the estimated magnetization reported in axial areas of the MAR and CIR, and in an axial area and an off-axis knoll of the southern Mariana Trough (Cordier et al. 2010; Fujii et al. 2015; Honsho et al. 2009). The NRM of zero-age basalt typically carries a strong intensity of several tens of $\mathrm{A} / \mathrm{m}$, although this intensity dramatically decreases to several $\mathrm{A} / \mathrm{m}$ with the age, following low-temperature oxidation (e.g., Gee and Kent 1994; Johnson and Tivey 1995). Therefore, a high magnetization zone can be interpreted here as relatively fresh basalt that erupted during the recent period. The primary TRM intensity of oceanic basalt is theoretically controlled by various variables such as the amount of titanomagnetite, the magnetic domain state distribution, the grain chemistry of titanomagnetite, and the strength of the past geomagnetic field. Although it is difficult to discuss quantitative criteria for freshness based on the remanence intensity, it can be noted that 

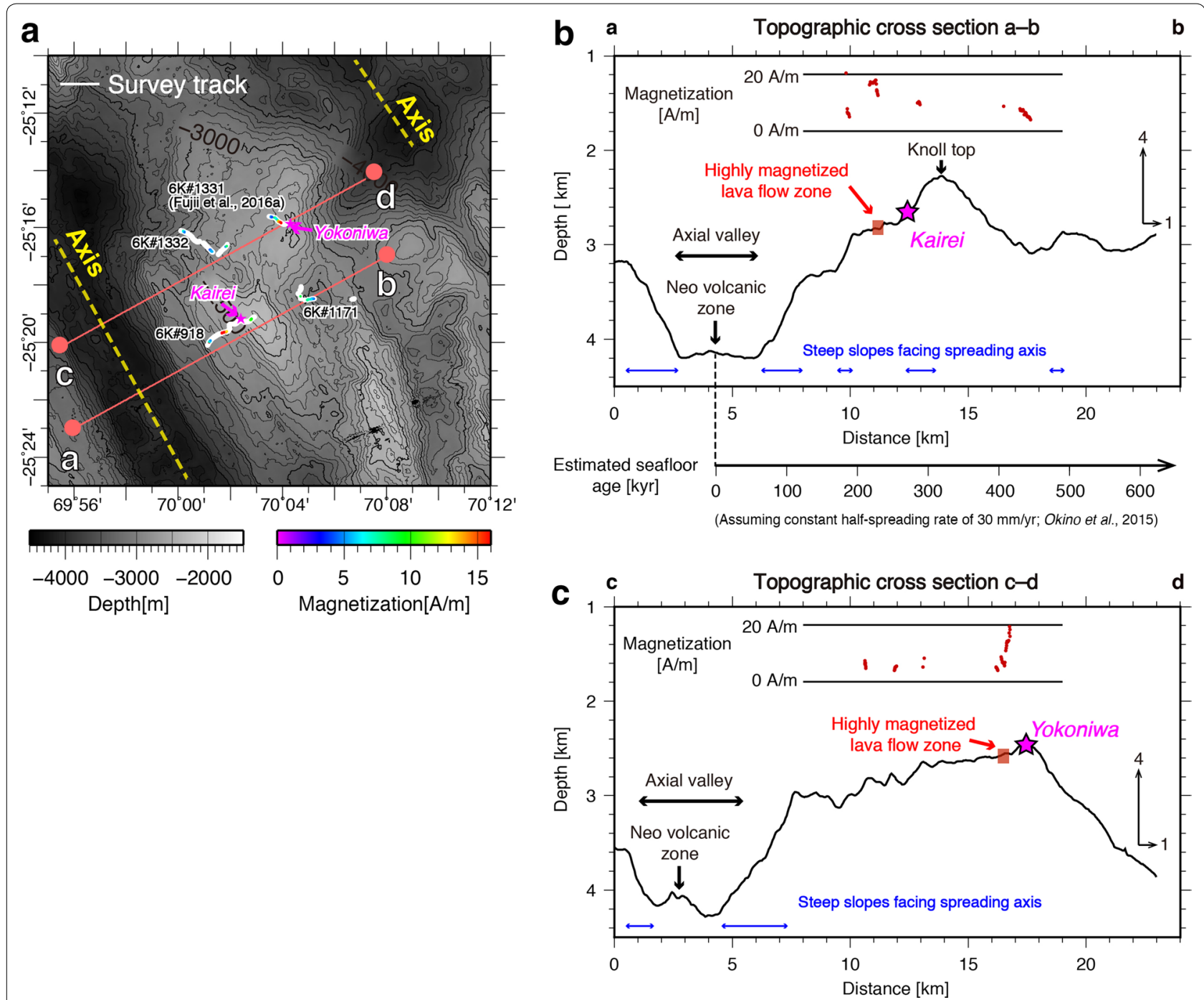

Fig. 7 Distribution of highly magnetized lava flows with normal polarity. a geographic distribution, $\mathbf{b}$ profile across the spreading axis to the off-axis area including the Kairei field, and $\mathbf{c}$ profile across the spreading axis to the off-axis area including the Yokoniwa field. Magnetization intensities of estimations with high coherency ( $>0.5$ in both $x$ and $z$ directions) and normal polarity (phase of from -30 to 30 in both $x$ and $z$ directions) are selected and shown as a rainbow-colored circle in (a) and as a black circle in (b) and (c). White circles in (a) show the observed area in which the estimation of absolute magnetization from magnetic anomaly was conducted. The raw data of magnetic anomaly along dive $6 \mathrm{~K} \# 1331$ are cited from Fujii et al. (2016a)

a magnetization intensity greater than $10 \mathrm{~A} / \mathrm{m}$ has not been generally observed in an off-axis seafloor millions of years old (Gee and Kent 1994; Johnson and Tivey 1995; Zhou et al. 2001). The highly magnetized lava flow zones $(\sim 20 \mathrm{~A} / \mathrm{m})$ in the study area are in a seafloor approximately $250 \mathrm{kyr}$ old if a constant half-spreading rate of $30 \mathrm{~mm} / \mathrm{yr}$ is assumed (Okino et al. 2015; Fig. 5). This intensity of $\sim 20 \mathrm{~A} / \mathrm{m}$ is too high for off-axis areas in case of an exponential reduction in the NRM intensity with a time constant of 20,000 to 100,000 years (Gee and Kent 1994; Johnson and Tivey 1995).
The rock magnetic properties of NRM and magnetic susceptibility for lava samples collected along dive $6 \mathrm{~K} \# 1331$ on the western slope of the Yokoniwa Rise have been reported by Fujii et al. (2016a). We additionally measured these for lava samples collected along dive $6 \mathrm{~K} \# 918$ on the western slope of the Hakuho Knoll. Rock samples were divided into four cubic sub-samples (2-cm cubic), which were utilized for measurements of NRM at the Atmosphere and Ocean Research Institute (AORI), the University of Tokyo using a spinner magnetometer (Natsuhara Giken DSPIN). Further, magnetic susceptibility was measured using an AGICO KLY-3 Kappabridge at 
Table 1 Rock magnetic and physical properties. Bulk grain density, natural remanent magnetization (NRM), magnetic susceptibility $(K)$, and Koenigsberger ratio $(Q)$ of 15 lava samples obtained in the dives $6 K \# 918$ and $6 K \# 1331$ were demonstrated

\begin{tabular}{|c|c|c|c|c|c|c|c|c|c|c|}
\hline Sample & $n$ & $\begin{array}{l}\text { Grain density } \\
\left(\mathrm{kg} / \mathrm{m}^{3}\right)\end{array}$ & $\operatorname{NRM}(\mathrm{A} / \mathrm{m})$ & $\sigma_{\mathrm{NRM}}(\mathrm{A} / \mathrm{m})$ & $K(\mathrm{SI})$ & $\sigma_{K}(\mathrm{SI})$ & $Q$ & Latitude $\left({ }^{\circ}\right)$ & Longitude $\left({ }^{\circ}\right)$ & Depth \\
\hline 6K\#918R01 & 4 & 2.98 & 8.2 & 0.5 & 0.0223 & 0.0011 & 10 & -25.3363 & 70.0180 & 2897 \\
\hline 6K\#918R02 & 4 & 2.98 & 6.4 & 0.4 & 0.0016 & 0.0001 & 115 & -25.3324 & 70.0207 & 2836 \\
\hline 6K\#918R03 & 4 & 2.96 & 18.4 & 1.6 & 0.0025 & 0.0002 & 209 & -25.3275 & 70.0293 & 2704 \\
\hline 6K\#918R06 & 4 & 2.99 & 11.5 & 0.9 & 0.0025 & 0.0004 & 129 & -25.3204 & 70.0400 & 2428 \\
\hline 6K\#918R07 & 4 & 2.99 & 2.9 & 0.3 & 0.0103 & 0.0022 & 8 & -25.3208 & 70.0415 & 2435 \\
\hline 6K\#918R08 & 4 & 3.09 & 4.2 & 0.1 & 0.0124 & 0.0003 & 9 & -25.3217 & 70.0428 & 2423 \\
\hline 6K\#918R09 & 4 & 3.09 & 5.6 & 0.4 & 0.0111 & 0.0002 & 14 & -25.3176 & 70.0500 & 2445 \\
\hline 6K\#918R10 & 4 & 3.01 & 8.2 & 1.4 & 0.0019 & 0.0004 & 122 & -25.3176 & 70.0500 & 2445 \\
\hline 6K\#918R11 & 4 & 3.03 & 11.2 & 3.8 & 0.0058 & 0.0026 & 54 & -25.3176 & 70.0500 & 2445 \\
\hline 6K\#1331R01 & 4 & 2.94 & 1.2 & 1.0 & 0.0007 & 0.0002 & 46 & -25.2600 & 70.0579 & 2622 \\
\hline 6K\#1331R02 & 4 & 2.96 & 0.9 & 0.4 & 0.0007 & 0.0001 & 34 & -25.2600 & 70.0579 & 2622 \\
\hline 6K\#1331R03 & 6 & 2.97 & 1.7 & 1.4 & 0.0008 & 0.0002 & 59 & -25.2610 & 70.0623 & 2556 \\
\hline 6K\#1331R04 & 5 & 2.96 & 1.3 & 0.7 & 0.0007 & 0.0001 & 51 & -25.2610 & 70.0623 & 2556 \\
\hline 6K\#1331R06 & 8 & 2.95 & 1.9 & 1.4 & 0.0008 & 0.0002 & 64 & -25.2632 & 70.0650 & 2560 \\
\hline 6K\#1331R07 & 4 & 2.97 & 1.8 & 1.8 & 0.0007 & 0.0001 & 74 & -25.2632 & 70.0650 & 2560 \\
\hline
\end{tabular}

The original data of the dive 6K\#1331 sample was cited from Fujii et al. (2016a)

$n$ Number of measured 2-cm cubic specimens, NRM natural remanent magnetization, $K$ magnetic susceptibility. Q Koenigsberger ratio (ratio of NRM to induced magnetization)

National Institute of Polar Research, and bulk grain density was measured using a high-precision microbalance and a gas pycnometer (AccuPycTM 1330 Pycnometer) at the AORI. All basaltic lava samples from dive 6K\#918 (Additional file 3: Figure S3) showed average NRM intensity values of $2.9-18.4 \mathrm{~A} / \mathrm{m}$ and magnetic susceptibility of 0.0016-0.0023 SI (Table 1; Fig. 8a). Measured data for all cubic specimens are shown in Additional file 5: Table S1. The lava NRM variation along dive $6 \mathrm{~K} \# 918$ is generally consistent with the magnetic anomaly-derived absolute magnetization there (MADAM; Figs. 3, 8b). In contrast, all basaltic lava samples from dive 6K\#1331 (Additional file 4: Figure S4) showed low NRM values, less than $2 \mathrm{~A} / \mathrm{m}$, and low magnetic susceptibility, less than $0.001 \mathrm{SI}$ (Table 1). This result is inconsistent with the higher values of MADAM (0.7-1.0 km area in Figs. 5, 8b). This difference between magnetization from magnetic anomalies and that from rock samples can be explained by the grain size heterogeneity within lava flows and/or the degree of low-temperature oxidation as discussed by Fujii et al. (2015). The results of the comparison between rock NRM and MADAM in this study are consistent with the results reported in the studies by Honsho et al. (2009) and Fujii et al. (2015) (Fig. 8b). Due to the degree of crystallization linked to rapid cooling, the magnetic grain size is smaller in the outcrop than in the interior of the lava flows occurring below the seafloor (e.g., Marshall and Cox 1971; Kent and Gee 1996). This results in the lowest NRM intensity on the lava surface, followed by a large increase from the glassy margin to the interior, which in turn is followed by a gradual decrease, and finally a peak further interior. This pattern of NRM intensity variation was observed in relationship rock NRM intensities along with magnetic susceptibility (Fig. 8a) when magnetic susceptibility increases is assumed to be representative of the degree of crystallization. In addition to magnetic grain size distribution, low-temperature oxidation process may provide weaker rock NRM than MADAM, which represents the bulk magnetization of the accumulated lava flows, because it must occur faster on the surface than in the interior of the lavas. Although, until now, the evidence for oxidation heterogeneity in lava has not been examined, the pattern that NRM of rock samples tend to be of smaller values $(<\sim 5 \mathrm{~A} / \mathrm{m})$ than MADAM (Fig. 8b) is common for the Central Indian Ridge (this study), southern Mariana Trough (Fujii et al. 2015) and Mid-Atlantic Ridge (Honsho et al. 2009). Figure 8 clearly shows that the NRM of rock samples does not have a one-to-one correlation with MADAM estimates. The rock NRM tends to be higher than MADAM for higher values, while it is lower than MADAM for lower values. The material investigation required to interpret this relationship remains to be conducted, but field-geophysical observation using near-seafloor magnetic anomalies can provide important insights into the sub-seafloor lava heterogeneity as well as its bulk magnetization. 

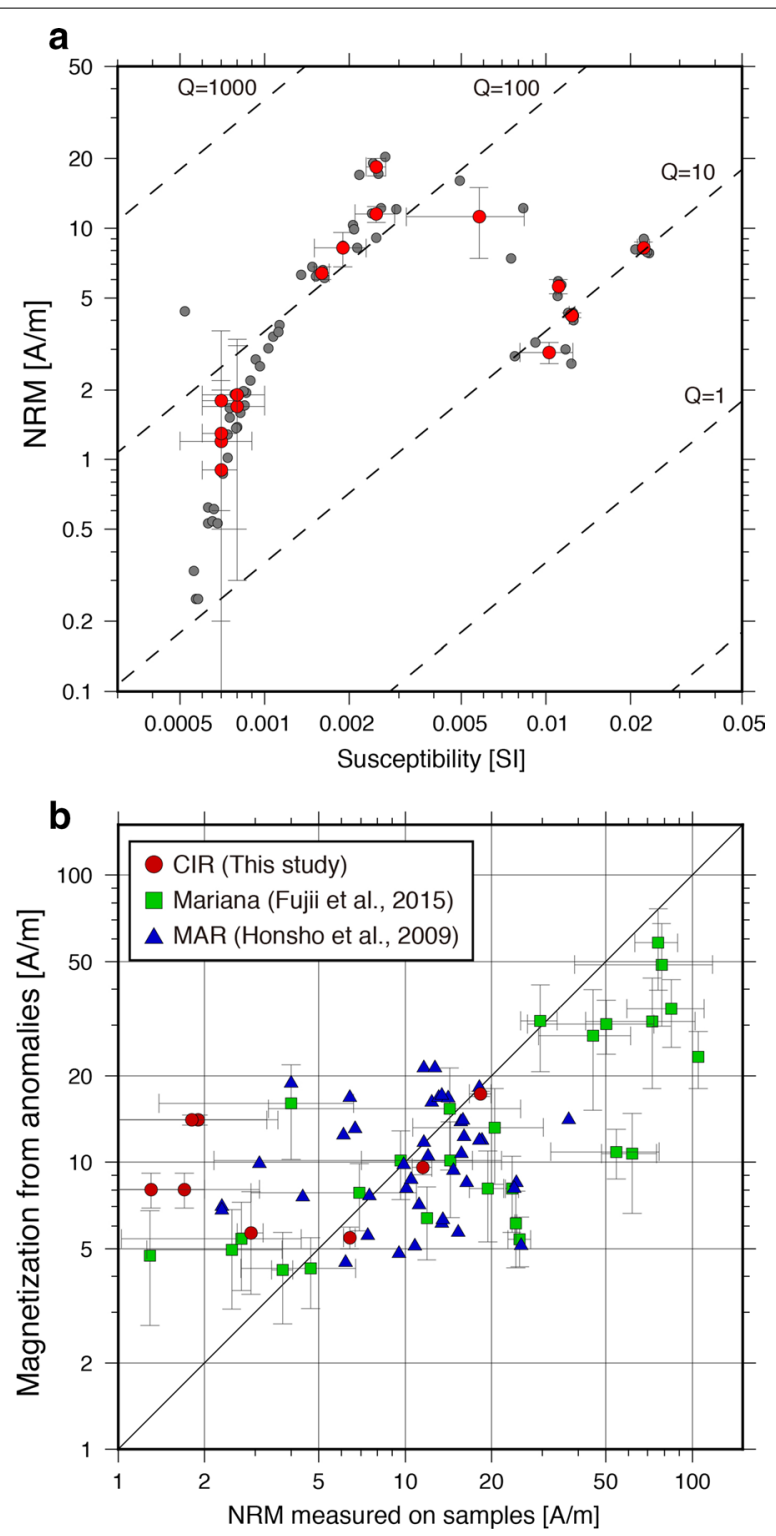

Fig. 8 a Log-log plot of magnetic susceptibility $(K ; \mathrm{SI})$ and natural remanent magnetization ( $N R M ; A / m$ ) of basaltic lava samples collected near the Kairei and Yokoniwa hydrothermal fields of the Central Indian Ridge. The broken lines show constant $Q$ values (Koenigsberger ratio) calculated for a magnetic field of 45,000 nT. The red circles show averaged values with standard deviations in each lava sample and the gray circles show each measured value for all cubic specimens. b Comparison between reliable magnetic-anomaly-derived absolute magnetization (MADAM) with high coherency ( $>0.5$ and $>0.3$ for 918R06) and NRM measured on rock samples. The applied MADAM corresponding to each rock NRM intensity was the average value near each rock sampling location (within $100 \mathrm{~m}$ ). The error bars along the $x$ - and $y$-axes show standard deviations of the NRM intensities and MADAM estimates for each point, respectively. The red circles show the data of the Central Indian Ridge (CIR) presented in this study. The green squares and blue triangles show previously reported data from the southern Mariana Trough (Fujii et al. 2015) and Mid-Atlantic Ridge (Honsho et al. 2009), respectively
Short-wavelength variations in magnetic anomalies within the Brunhes Chron can be created by geomagnetic field intensity variation. Studies on near-seafloor magnetic anomalies at different spreading centers (Gee et al. 2000; Pouliquen et al. 2001; Honsho et al. 2009; Cordier et al. 2010) show that the magnetic anomalies recorded near the oceanic crust are related to temporal variations in geomagnetic intensity (e.g., Guyodo and Valet 1999). The estimates of paleointensity variations from submarine basaltic glasses are remarkably similar to those documented from independent palaeointensity records over the past several tens of thousands of years, and they have been used to determine the eruptive ages of young mid-ocean ridge lava flows (e.g., Carlut and Kent 2000; Gee et al. 2000; Bowles et al. 2006; Searle et al. 2010). The magnetic data shown in this study did not cover the area extending from the spreading axis to off-axis regions, and therefore, it is difficult to compare the obtained profile to the paleointensity variation with considerable certainty. If a constant half-spreading rate of $30 \mathrm{~mm} / \mathrm{yr}$ is assumed here (Okino et al. 2015), the age of the studied seafloor along dive 6K\#918 is approximately 200-300 kyr (Fig. 7). For this period, the local maximum of geomagnetic paleointensity is certainly shown in global stacks of reliable relative paleointensity records from marine sediments (Valet et al. 2005; Channell et al. 2009). Cordier et al. (2010) reported continuous across-axis distribution of absolute magnetization of the CIR covering the last $800 \mathrm{kyr}$ period estimated using near-seafloor magnetic data acquired during the submersible Nautile dives and the analytical method of Honsho et al. (2009). The obtained absolute magnetization intensity shows a maximum value of $\sim 20 \mathrm{~A} / \mathrm{m}$ at the spreading center, and a local maximum value of $\sim 10 \mathrm{~A} / \mathrm{m}$ in the $190-280$-kyr-old seafloor. Since the lack of off-axis volcanism is reinforced by the backscatter images and K-Ar ages obtained for a few samples in this area (Cordier et al. 2010), approximately $10 \mathrm{~A} / \mathrm{m}$ can be regarded as the normal signature for the uppermost crustal magnetization during this age. Therefore, we considered that paleointensity variation could not be a significant factor to provide the seafloor magnetization intensity of $20 \mathrm{~A} / \mathrm{m}$, as seen along the dive $6 \mathrm{~K} \# 918$, on off-axis seafloors over the effect of low-temperature oxidation.

**The magnitude of TRM is proportional to the strength of the ambient geomagnetic field and also depends on geochemistry, such as the iron content of the rocks. Good linear correlations between NRM and $\mathrm{FeO}$ content were obtained from the dredge samples of the southern East Pacific Rise (EPR), upon calculation using the microprobe analysis of glass chips (Gee and Kent 1997). This result indicates that the magnetization of abyssal basalts can 
vary by up to a factor of 4 as a function of their iron content alone, from about $12 \mathrm{~A} / \mathrm{m}$ for $9 \mathrm{wt} \% \mathrm{FeO}$ to $>50 \mathrm{~A} / \mathrm{m}$ for the highest $\mathrm{FeO}$ values of $\sim 15 \mathrm{wt} \%$. Three basalt samples, 6K\#918R02, 6K\#918R02, and 6K\#918R10, collected near the KHF show FeO content of 8.1-8.4 wt\%, as measured by the aforementioned microprobe analysis (Kumagai et al. 2008; Additional file 5: Table S1). These values are comparable to lower end-members of the NRM-FeO relationship of the EPR (Gee and Kent 1997), suggesting that the primary TRM intensity of basaltic lavas near the KHF tends to be smaller because of the low-iron content of the parent magma. Therefore, the geochemical data for lava samples do not contradict our interpretation that the estimated high magnetization intensity of $20 \mathrm{~A} / \mathrm{m}$ here is indicative of a recent eruption.

Our estimation of the magnetization intensity of $20 \mathrm{~A} / \mathrm{m}$ for the highly magnetized off-axis lava flows in the present study, along with the result of the rock magnetic, geochemical, and magnetic anomaly studies from other regions, implies that the basaltic volcanic eruption may have occurred in the off-axis knolls near KHF and YHF during the recent period (Fig. 7). Moreover, it is noteworthy that for both KHF and YHF, which are demonstrably accompanied by recent eruptions, the highly magnetized lavas with estimated magnetization intensities of up to $20 \mathrm{~A} / \mathrm{m}$ were observed only near their western slope bottoms. We speculate that this offaxis volcanic activity might be the source of heat for the hydrothermal circulation within the KHF and YHF. The duration of hydrothermal circulation is essentially controlled by the duration and depth of the volcanic activity. The reported life-span of seafloor intermittent hydrothermal activity is for $100-1000$ years at a fast-spreading ridge for a short-lived system (Haymon et al. 1991, 1993), and 140,000 years at the detachment-fault-controlled slow-spreading ridges for a long-lived system (Humphris and Cann 2000; Lalou et al. 1995). Although the mechanism and actual conditions of this off-axis volcanism cannot be determined because of inadequate geophysical data; the time-span of recent eruptions $(<20,000$ $100,000 \mathrm{kyr}$ ) estimated from magnetization intensities, matches those of the hydrothermal systems known from the presently active KHF and elsewhere. Further investigation of the detailed sub-seafloor structure and heat flow studies are needed for better understanding of the circulation style and duration of hydrothermal systems.

\section{Conclusion}

We conducted near-seafloor magnetic field measurements and rock magnetic and geochemical studies of seafloor lava flows using the submersible SHINKAI 6500 near the Kairei and Yokoniwa hydrothermal fields of the Central Indian Ridge. The integrated analysis of the magnetic anomaly and comparison with the rock magnetic properties led to the following conclusions:

1. The Kairei hydrothermal field is associated with a lack of magnetization and it extends several hundred meters toward the western slope. The hydrothermal alteration of magnetic minerals present in extrusive lavas and in deposits of nonmagnetic hydrothermal material are likely responsible for the reduced magnetization.

2. The MADAM estimates are generally consistent with the NRM intensities of collected rock samples from the corresponding seafloor lava, although the NRM values are partly smaller than the MADAM estimates for low values. This discrepancy can be explained by the heterogeneity in magnetic grain size distribution as well as the spatial difference in the degree of lowtemperature oxidation.

3. The magnetization intensity from magnetic anomalies reaches $20 \mathrm{~A} / \mathrm{m}$ in the study area, which is clearly greater than that of previously reported offaxis areas. This result suggests that a recent volcanic eruption may have occurred in the off-axis areas. High magnetization distributions are commonly observed at the bottoms of the western slopes of the KHF and YHF. This finding provides new insight into the distribution of highly magnetized lava flows in off-axis areas and indicates the distribution of recent off-axis volcanic activities, which is potentially linked to the sub-seafloor hydrothermal circulation.

\section{Additional file}

Additional file 1: Figure S1. Analysis of observed magnetic anomaly along the $6 \mathrm{~K} \# 1171$ track assuming a magnetization direction parallel to the geocentric axial-dipole field; an inclination of $-43^{\circ}$ and a declination of $0^{\circ}$. From top to bottom: observed (red line) and synthetic (blue line) magnetic anomaly intensity of $x, y$, and $z$ components, magnetization, phase, vehicle altitude, and seafloor/vehicle geometry. Black and gray circles are those with high coherency of $>0.5$ and from $0.3-0.5$ on both the $x$ and $z$ components, respectively. The profile was divided into four sections depending on the survey direction, which is essential for two-dimensional analysis of magnetic anomalies. WL, window length.

Additional file 2: Figure S2. Analysis of observed magnetic anomaly along the $6 \mathrm{~K} \# 1332$ track assuming a magnetization direction parallel to the geocentric axial-dipole field; an inclination of $-43^{\circ}$ and a declination of $0^{\circ}$. From top to bottom: observed (red line) and synthetic (blue line) magnetic anomaly intensity of $x, y$, and $z$ components, magnetization, phase, vehicle altitude, and seafloor/vehicle geometry. Black and gray circles are those with high coherency of $>0.5$ and from $0.3-0.5$ on both the $x$ and $z$ components, respectively. The profile was divided into three sections depending on the survey direction, which is essential for two-dimensional analysis of magnetic anomalies. $\mathrm{WL}$, window length.

Additional file 3: Figure S3. Photograph of collected basaltic rock samples during the dive 6K\#918 near the Kaire hydrothermal field of the Central 
Indian Ridge. Photographic data are cited from Data and Sample Research System for Whole Cruise Information "DARWIN" manage by JAMSTEC (http://www.godac.jamstec.go.jp/darwin/).

Additional file 4: Figure S4. Photo image of collected basaltic rock samples during the dive 6K\#1331 near the Yokoniwa hydrothermal field of the Central Indian Ridge. Photographic data are cited from Data and Sample Research System for Whole Cruise Information "DARWIN" manage by JAMSTEC (http://www.godac.jamstec.go.jp/darwin/).

Additional file 5: Table 51. Major element composition for lava samples collected along the dive 6K\#918 near the Kairei hydrothermal field. The data were cited from Kumagai et al. (2008).

\section{Abbreviations}

CIR: Central Indian Ridge; CRM: chemical remanent magnetization; IGRF: International Geomagnetic Reference Field; KHF: Kairei hydrothermal field; NRM: natural remanent magnetization; TRM: thermoremanent magnetization; YHF: Yokoniwa hydrothermal field.

\section{Authors' contributions}

MF was involved in data analysis, data interpretation, and manuscript preparation. KO was involved in data acquisition, and manuscript preparation. Both authors read and approved the final manuscript.

\section{Author details}

${ }^{1}$ National Institute of Polar Research, 10-3 Midoricho, Tachikawa, Tokyo 190-8518, Japan. ${ }^{2}$ SOKENDAI (The Graduate University for Advanced Studies), Shonan Village, Hayama, Kanagawa 240-0193, Japan. ${ }^{3}$ Atmosphere and Ocean Research Institute, The University of Tokyo, 5-1-5, Kashiwanoha, Kashiwa-shi, Chiba 277-8564, Japan.

\section{Acknowledgements}

The authors are grateful to the crew of the RN Yokosuka and the support teams of the submersible SHINKAI 6500. In addition, the authors thank the onboard scientists of the YK05-16, YK09-13, and YK13-03 and Hideyuki Kumagai for providing dive data. Discussions with Kentaro Nakamura, Hideyuki Kumagai, Hiroshi Sato, Taichi Sato, and Tomoyuki Morishita were beneficial for writing this manuscript. We express our sincere appreciation to Y. Yamamoto and T. Yamazaki for their kind support with conducting rock magnetic measurements. This study was supported by a cooperative research program of the Center for Advanced Marine Core Research, Kochi University, and the Cooperative Program (2016) of Atmosphere and Ocean Research Institute, The University of Tokyo. The GANSEKI database by JAMSTEC was utilized for rock magnetic analysis. This work was supported by JSPS KAKENHI grants JP18K13638 and JP18H01317. John Tarduno, Roi Granot, and two anonymous reviewers are thanked for providing constructive suggestions.

\section{Competing interests}

The authors declare that they have no competing interests.

\section{Availability of data and materials}

The results of all obtained magnetic data are displayed in Figs. 2 and 4, and their details are described in the manuscript.

\section{Consent for publication}

Not applicable.

\section{Funding}

This work was supported by JSPS KAKENHI grants \#JP18K13638 and \#JP18H01317.

\section{Publisher's Note}

Springer Nature remains neutral with regard to jurisdictional claims in published maps and institutional affiliations.

Received: 17 April 2018 Accepted: 13 November 2018 Published online: 04 December 2018

\section{References}

Ade-Hall JM, Palmer HC, Hubbard TP (1971) The magnetic and opaque petrological response of basalts to regional hydrothermal alteration. Geophys J R Astron Soc 24:137-174. https://doi.org/10.1111/j.1365-246X.1971. tb02171.x

Bowles J, Gee JS, Kent DV, Perfit MR, Soule SA, Fornari DJ (2006) Paleointensity applications to timing and extent of eruptive activity, $9^{\circ}-10^{\circ} \mathrm{N}$ East Pacific Rise. Geochem Geophys Geosyst. https://doi.org/10.1029/2005gc001141

Caratori Tontini F, de Ronde CEJ, Yoerger D, Kinsey J, Tivey M (2012) 3-D focused inversion of near-seafloor magnetic data with application to the Brothers volcano hydrothermal system, Southern Pacific Ocean, New Zealand. J Geophys Res Solid Earth 117:B10102. https://doi. org/10.1029/2012JB009349

Caratori Tontini F, Bortoluzzi G, Carmisciano C et al (2014a) Near-bottom magnetic signatures of submarine hydrothermal systems at Marsili and Palinuro Volcanoes, Southern Tyrrhenian Sea, Italy. Econ Geol 109:21192128. https://doi.org/10.2113/econgeo.109.8.2119

Caratori Tontini F, Bortoluzzi G, Carmisciano C et al (2014b) Near-bottom magnetic signatures of submarine hydrothermal systems at Marsili and Palinuro Volcanoes, Southern Tyrrhenian Sea, Italy. Econ Geol 109:21192128. https://doi.org/10.2113/econgeo.109.8.2119

Carlut J, Kent DV (2000) Paleointensity record in zero-age submarine basalt glasses: testing a new dating technique for recent MORBs. Earth Planet Sci Lett 183:389-401. https://doi.org/10.1016/S0012-821X(00)00291-0

Channell JET, Xuan C, Hodell DA (2009) Stacking paleointensity and oxygen isotope data for the last 1.5 Myr (PISO-1500). Earth Planet Sci Lett 283:14-23. https://doi.org/10.1016/j.epsl.2009.03.012

Cordier C, Benoit M, Hémond C, et al (2010) Time scales of melt extraction revealed by distribution of lava composition across a ridge axis. Geochemistry, Geophys Geosystems 11:. https://doi.org/10.1029/2010g c003074

Doubrovine PV, Tarduno JA (2006) Alteration and self-reversal in oceanic basalts. J Geophys Res 111:B12S30. https://doi.org/10.1029/2006JB0044 68

Elderfield H, Schultz A (1996) Mid-ocean ridge hydrothermal fluxes and the chemical composition of the ocean. Annu Rev Earth Planet Sci 24:191-224. https://doi.org/10.1146/annurev.earth.24.1.191

Fujii M, Okino K, Honsho C, Dyment J, Szitkar F, Mochizuki N, Asada M (2015) High-resolution magnetic signature of active hydrothermal systems in the back-arc spreading region of the southern Mariana Trough. J Geophys Res Solid Earth 120:2821-2837. https://doi.org/10.1002/2014JB011714

Fujii M, Okino K, Sato T, Sato H, Nakamura K (2016a) Origin of magnetic highs at ultramafic hosted hydrothermal systems: insights from the Yokoniwa site of Central Indian Ridge. Earth Planet Sci Lett 441:26-37. https://doi. org/10.1016/j.epsl.2016.02.018

Fujii M, Okino K, Sato H, Nakamura K, Sato T, Yamazaki T (2016b) Variation in magnetic properties of serpentinized peridotites exposed on the Yokoniwa Rise, Central Indian Ridge: Insights into the role of magnetite in serpentinization. Geochem Geophy Geosy 17:5024-5035. https:// doi.org/10.1002/2016gc006511

Fujii M, Sato H, Togawa E, Shimada K, Ishibashi J (2018) Seafloor hydrothermal alteration affecting magnetic properties of abyssal basaltic rocks: Insights from back-arc lavas of the Okinawa Trough. Earth Planets Space. https://doi.org/10.1186/s40623-018-0958-6

Gallant MR, Von Damm KL (2006) Geochemical controls on hydrothermal fluids from the Kairei and Edmond Vent Fields, $23^{\circ}-25^{\circ} \mathrm{S}$, Central Indian Ridge. Geochem Geophy Geosy 7. https://doi.org/10.1029/2005gc0010 67

Gamo T, Chiba H, Yamanaka T, Okudaira T, Hashimoto J, Tsuchida S, Ishibashi J, Kataoka S, Tsunogai U, Okamura K, Sano Y, Shinjo R (2001) Chemical characteristics of newly discovered black smoker fluids and associated hydrothermal plumes at the Rodriguez Triple Junction, Central Indian Ridge. Earth Planet Sci Lett 193:371-379. https://doi.org/10.1016/ S0012-821X(01)00511-8

Gee J, Kent DV (1994) Variations in layer 2A thickness and the origin of the central anomaly magnetic high. Geophys Res Lett 21:297-300. https:// doi.org/10.1029/93GL03422

Gee J, Kent DV (1997) Magnetization of axial lavas from the southern East Pacific Rise $\left(14^{\circ}-23^{\circ} \mathrm{S}\right)$ : geochemical controls on magnetic properties. J Geophys Res 102:24873-24886. https://doi.org/10.1029/97JB02544 
Gee JS, Cande SC, Hildebrand JA, Donnelly K, Parker RL (2000) Geomagnetic intensity variations over the past 780 kyr obtained from near-seafloor magnetic anomalies. Nature 408:827-832

Guyodo Y, Valet J-P (1999) Global changes in intensity of the Earth's magnetic field during the past $800 \mathrm{kyr}$. Nature 399:249-252

Hall JM (1992) Interaction of submarine volcanic and high-temperature hydrothermal activity proposed for the formation of the Agrokipia, volcanic massive sulfide deposits of Cyprus. Can J Earth Sci 29:1928-1936. https://doi.org/10.1139/e92-150

Haymon RM, Fornari DJ, Edwards MH, Carbotte S, Wright D, Macdonald KC (1991) Hydrothermal vent distribution along the East Pacific Rise crest $\left(9^{\circ} 09^{\prime}-54^{\prime} \mathrm{N}\right)$ and its relationship to magmatic and tectonic processes on fast-spreading mid-ocean ridges. Earth Planet Sci Lett 104:513-534. https://doi.org/10.1016/0012-821X(91)90226-8

Haymon RM, Fornari DJ, Von Damm KL, Lilley MD, Perfit MR, Edmond JM, Shanks WC, Lutz RA, Grebmeier JM, Carbotte S, Wright D, McLaughlin E, Smith M, Beedle N, Olson E (1993) Volcanic eruption of the mid-ocean ridge along the East Pacific Rise crest at $9^{\circ} 45-52^{\prime} \mathrm{N}$ : direct submersible observations of seafloor phenomena associated with an eruption event in April, 1991. Earth Planet Sci Lett 119:85-101. https://doi. org/10.1016/0012-821X(93)90008-W

Hochstein MP, Soengkono S (1997) Magnetic anomalies associated with high temperature 779 reservoirs in the Taupo volcanic zone (New Zealand). Geothermics 26:1-24

Honsho C, Tamaki K, Fujimoto H (1996) Three-dimensional magnetic and gravity studies of the Rodriguez Triple Junction in the Indian Ocean. J Geophys Res Solid Earth 101:15837-15848. https://doi. org/10.1029/96JB00644

Honsho C, Dyment J, Tamaki K, Ravilly M, Horen H, Gente P (2009) Magnetic structure of a slow spreading ridge segment: insights from near-bottom magnetic measurements on board a submersible. J Geophys Res 114:B05101. https://doi.org/10.1029/2008JB005915

Honsho C, Ura T, Kim K (2013) Deep-sea magnetic vector anomalies over the Hakurei hydrothermal field and the Bayonnaise knoll caldera, IzuOgasawara arc, Japan. J Geophys Res Solid Earth 118:5147-5164. https ://doi.org/10.1002/jgrb.50382

Humphris SE, Cann JR (2000) Constraints on the energy and chemical balances of the modern TAG and ancient Cyprus seafloor sulfide deposits. J Geophys Res 105:28477. https://doi.org/10.1029/2000JB900289

International Association of Geomagnetism and Aeronomy (IAGA) Working Group V-MOD (2010) International Geomagnetic Reference Field: the eleventh generation. Geophys J Int 183:1216-1230. https://doi. org/10.1111/j.1365-246X.2010.04804.x

Irving E (1970) The Mid-Atlantic Ridge at $45^{\circ} \mathrm{N}$. XIV. Oxidation and magnetic properties of basalt; review and discussion. Can J Earth Sci 7:15281538. https://doi.org/10.1139/e70-144

Isezaki N (1986) A new shipboard three-component magnetometer. Geophysics 51:1992-1998. https://doi.org/10.1190/1.1442054

Johnson HP, Atwater T (1977) Magnetic study of basalts from the MidAtlantic Ridge, lat 37N. Geol Soc Am Bull 88:637-647. https://doi. org/10.1130/0016-7606(1977)88\%3c637:MSOBFT\%3e2.0.CO;2

Johnson HP, Tivey MA (1995) Magnetic properties of zero-age oceanic crust: a new submarine lava flow on the Juan de Fuca Ridge. Geophys Res Lett 22:175-178. https://doi.org/10.1029/94GL02053

Kent DV, Gee J (1996) Magnetic alteration of zero-age oceanic basalt. Geology 24:703-706. https://doi.org/10.1130/0091-7613(1996)024\%3c070 3:MAOZAO\%3e2.3.CO;2

Kumagai H, Nakamura K, Toki T, Morishita T, Okino K, Ishibashi J, Tsunogai U, Kawagucci S, Gamo T, Shibuya T, Sawaguchi T, Neo N, Joshima M, Sato T, Takai K (2008) Geological background of the Kairei and Edmond hydrothermal fields along the Central Indian Ridge: implications of their vent fluids' distinct chemistry. Geofluids 8:239-251. https://doi.org/10.111 1/j.1468-8123.2008.00223.x

Lalou C, Reyss J-L, Brichet E, Rona PA, Thompson G (1995) Hydrothermal activity on a $10^{5}$ year scale at a slow-spreading ridge, TAG hydrothermal field, Mid-Atlantic Ridge $26^{\circ}$ N. J Geophys Res 100:17855. https://doi. org/10.1029/95JB01858

Marshall M, Cox A (1971) Magnetism of Pillow Basalts and Their Petrology. Geol Soc Am Bull 82:537-552. https://doi.org/10.1130/00167606(1971)82\%5b537:MOPBAT\%5d2.0.CO;2

Mendel V, Sauter D, Patriat P, Munschy M (2000) Relationship of the Central Indian Ridge segmentation with the evolution of the Rodrigues Triple Junction for the past 8 Myr. J Geophys Res Solid Earth 105:16563-16575. https://doi.org/10.1029/2000JB900098

Nakamura K, Morishita T, Bach W, Klein F, Hara K, Okino K, Takai K, Kumagai H (2009) Serpentinized troctolites exposed near the Kairei Hydrothermal Field, Central Indian Ridge: insights into the origin of the Kairei hydrothermal fluid supporting a unique microbial ecosystem. Earth Planet Sci Lett 280:128-136. https://doi.org/10.1016/j.epsl.2009.01.024

O'Reilly W, Banerjee SK (1966) Oxidation of Titanomagnetites and Self-Reversal. Nature 211:26-28

Okino K, Nakamura K, Sato H (2015) Tectonic background of four hydrothermal fields along the Central Indian Ridge, In: Ishibashi J, Okino K, Sunamura M (Eds.), Subseafloor Biosphere Linked to Hydrothermal Systems SE-11. Springer Japan, pp. 133-146. https://doi.org/10.1007/978-4-431-54865-2_11

Pouliquen G, Gallet Y, Dyment J, Patriat P, Tamura C (2001) A geomagnetic record over the last 3.5 million years from deep-tow magnetic anomaly profiles across the Central Indian Ridge. J Geophys Res Solid Earth 106:10941-10960. https://doi.org/10.1029/2000JB900442

Sato T, Okino K, Kumagai H (2009) Magnetic structure of an oceanic core complex at the southernmost Central Indian Ridge: analysis of shipboard and deep-sea three-component magnetometer data. Geochem Geophy Geosy 10:Q06003. https://doi.org/10.1029/2008GC002267

Sato H, Nakamura K, Kumagai H, Senda R, Morishita T, Tamura A, Arai S (2015) Petrology and Geochemistry of Mid-Ocean Ridge Basalts from the Southern Central Indian Ridge. In: Ishibashi J, Okino K, Sunamura M (eds) Subseafloor Biosphere Linked to Hydrothermal Systems SE-13. Springer, Japan, pp 163-175. https://doi.org/10.1007/978-4-431-548652_13.

Searle RC, Murton BJ, Achenbach K et al (2010) Structure and development of an axial volcanic ridge: mid-Atlantic Ridge, $45^{\circ} \mathrm{N}$. Earth Planet Sci Lett 299:228-241. https://doi.org/10.1016/j.epsl.2010.09.003

Szitkar F, Dyment J, Choi Y, Fouquet Y (2014) What causes low magnetization at basalt-hosted hydrothermal sites? Insights from inactive site Krasnov (MAR 16³ $38^{\prime} \mathrm{N}$ ). Geochem Geophy Geosy 15:1441-1451. https://doi. org/10.1002/2014GC005284

Szitkar F, Petersen S, Caratori Tontini F, Cocchi L (2015) High-resolution magnetics reveal the deep structure of a volcanic-arc-related basalt-hosted hydrothermal site (Palinuro, Tyrrhenian Sea). Geochem Geophy Geosy 16:1950-1961. https://doi.org/10.1002/2015GC005769

Talwani M, Heirtzler JR (1964) In: Parks GA (ed) Computers in the Mineral Industries., pp 464-480

Tivey MA, Dyment J (2010) The magnetic signature of hydrothermal systems in slow spreading environments. Diversity of Hydrothermal Systems on Slow Spreading Ocean Ridges. AGU, Washington, DC, pp 43-66

Tivey MA, Johnson HP (2002) Crustal magnetization shows subsurface structure of Juan de Fuca Ridge hydrothermal vent fields. Geology 30:979-982

Tivey MA, Rona PA, Schouten H (1993) Reduced crustal magnetization beneath the active sulfide mound, TAG hydrothermal field, Mid-Atlantic Ridge at $26^{\circ} \mathrm{N}$. Earth Planet Sci Lett 115:101-115. https://doi.org/10.1016/0012821X(93)90216-V

Tivey MA, Johnson HP, Salmi MS, Hutnak M (2014) High-resolution nearbottom vector magnetic anomalies over Raven Hydrothermal Field, Endeavour Segment, Juan de Fuca Ridge. J Geophys Res Solid Earth 119:2014JB011223. https://doi.org/10.1002/2014JB011223

Valet J-P, Meynadier L, Guyodo Y (2005) Geomagnetic dipole strength and reversal rate over the past two million years. Nature 435:802

Verhoogen $J$ (1956) lonic ordering and self-reversal of magnetization in impure magnetites. J Geophys Res 61:201-209. https://doi.org/10.1029/ JZ061i002p00201 
Watkins ND, Paster TP (1971) The Magnetic Properties of Igneous Rocks from the Ocean Floor. Philos Trans R Soc London A Math Phys Eng Sci 268:507-550

Wooldridge AL, Harrison CGA, Tivey MA et al (1992) Magnetic Modeling Near Selected Areas of Hydrothermal Activity on the Mid-Atlantic and Gorda Ridges. J Geophys Res 97:10911-10926. https://doi.org/10.1029/92JB0 0605

Zhou W, Van der Voo R, Peacor DR et al (2001) Low-temperature oxidation in MORB of titanomagnetite to titanomaghemite: a gradual process with implications for marine magnetic anomaly amplitudes. J Geophys Res 106:6409-6421. https://doi.org/10.1029/2000JB900447

Zhu J, Lin J, Chen YJ, Tao C, German CR, Yoerger DR, Tivey MA (2010) A reduced crustal magnetization zone near the first observed active hydrothermal vent field on the Southwest Indian Ridge. Geophys Res Lett 37:L18303. https://doi.org/10.1029/2010GL043542

\section{Submit your manuscript to a SpringerOpen ${ }^{\circ}$ journal and benefit from:}

- Convenient online submission

- Rigorous peer review

- Open access: articles freely available online

- High visibility within the field

- Retaining the copyright to your article 